\title{
Drug-Induced Cicatricial Pemphigoid and Acquired Epidermolysis Bullosa
}

\author{
THEODOOR VAN JOOST, MD \\ ALBERT J. VAN'T VEEN, MD
}

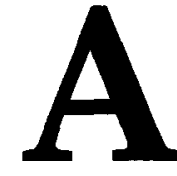
utoimmune diseases probably have a multitude of causes. It is obvious that exogenous agents, particularly drugs, may trigger the development of autoimmune responses leading to bullous eruptions. In the literature several cases of drug-induced (disseminated) bullous pemphigoid (BP) have been reported (see article by Fellner in this issue); however, localized variants of pemphigoid and acquired epidermolysis bullosa, although to a lesser extent, apparently can also be induced by drugs.

Important localized variants of pemphigoid are cicatricial pemphigoid (CP) (synonyms: mucous membrane pemphigoid [MMP], ocular pemphigoid) and two nonmucosal localized variants: the non-mucosal scarring type pemphigoid (Brunsting-Perry type) and the nonscarring localized-type pemphigoid (LBP).

Cicatricial pemphigoid is a rather rare disease of late middle age that occurs particularly on the mucous membranes of the eyes, oropharynx, genitalia, or anus. The characteristic skin picture is that of localized recurrent blisters with the development of scarring. ${ }^{1}$ The cicatricial process can cause serious adhesions, strictures, and depending on the localization, on the long-term loss of function. Histologically, in contrast to BP, eosinophils in LBP and CP are usually present in significantly small numbers. Particularly in CP lesions, a fairly dense, sometimes predominant lymphocytic inflammatory infiltrate is observed in the dermis.

Immunofluorescence (IF) studies in CP show a linear deposition of $\operatorname{IgG}$ and complement along the basement

From the Department of Dermato-Venereology, Erasmus University Rotterdam/Academic Hospital Rotterdam-Dijkzigt, Rotterdam, The Netherlands.

Address correspondence to Th. van Joost, MD, Department of Dermatovenereology, Erasmus University Rotterdam/Academic Hospital Rotterdam-Dijkzigt, Dr. Molewaterplein 40, 3015 GD Rotterdam, The Netherlands. membrane of lesional and perilesional skin, but circulating serum autoantibodies with affinity for the basement membrane are detectable in only a minority of the patients. $^{2}$

Several authors have reported cases classified as $\mathrm{CP}$ or MMP, apparently triggered by drugs ${ }^{3-11}$ (Table 1). Two cases of drug-induced $\mathrm{CP}^{3,6}$ are discussed here in more detail.

\section{Case Report 1}

A man, aged 46 years, who had been treated long-term with practolol (Eraldin) (daily oral dose $600 \mathrm{mg}$ ) for angina developed, after 2.5 years of usage, a chronic bilateral inflammatory blistering eruption on the ocular mucous membranes of the eyes leading to fibrosis and cicatrization with histologic and immunologic features compatible with CP (Figure 1). Small papules and vesicles were observed in infiltrated erythematous areas on the conjunctivae together with focal scarring and shrinkage. At that time, the patient also had a psoriasiform rash localized on the chest and the extremities. Five weeks after stopping practolol no new active lesions on the conjunctivae were noted, but the old lesions remained unresolved. Epicutaneous and intracutaneous skin tests with practolol at that time (1975) were negative.

Histopathologic examination of the lesional ocular mucous membrane adjacent to a blister showed subepithelial cleavage at the basement membrane. An infiltrate composed largely of lymphocytes with some eosinophils and plasmacytes and a large number of dilated blood vessels was observed in the submucosa.

Immunofluorescence studies on sections of the lesional mucosa adjacent to a blister showed a linear bandlike fluorescence in the subepithelial regions with antisera against IgG and complement, but because of tissue degeneration of the epithelium at these sites, the interpretation of the staining was less significant for a definite 
Table 1. Data in the Literature on Drug-Induced Cicatricial Pemphigoid*: Localization of the Lesions and Systemic or Topical Drugs Considered to Be Responsible for Eliciting the Syndrome

\begin{tabular}{|c|c|c|c|c|}
\hline Authors & $\mathrm{N}+$ & $I F \ddagger$ & Localization & Drug Responsible \\
\hline Van Joost et $\mathrm{al}^{3}$ & 1 & Positive & Ocular & Oral practolol \\
\hline Pattern et $\mathrm{al}^{4}$ & 2 & $\S$ & Ocular (2)ף & $\begin{array}{l}\text { Topical echothiophate } \\
\text { iodide (2) }\end{array}$ \\
\hline Pegum and Pembroke ${ }^{5}$ & 1 & $\S(?)$ & Ocular and oral & Oral D-penicillamine \\
\hline Van Joost et $\mathrm{al}^{6}$ & 1 & Positive & Vulval, anal, and perianal & Oral clonidine \\
\hline Hirst et $\mathrm{al}^{7}$ & 2 & $\S(?)$ & Ocular (2) & $\begin{array}{l}\text { Topical pilocarpine (1) } \\
\text { Topical demecarium } \\
\text { Bromide (1) }\end{array}$ \\
\hline $\begin{array}{l}\text { Shuttleworth and } \\
\text { Graham-Brown }\end{array}$ & 1 & Positive & Ocular, oral, cutaneous & Oral D-penicillamine \\
\hline $\begin{array}{l}\text { Harrington and } \\
\text { Messenger }\end{array}$ & 2 & Positive & $\begin{array}{l}\text { Oral and cutaneous (1) } \\
\text { Ocular, oral, and } \\
\text { cutaneous (1) }\end{array}$ & Oral indomethacin (2) \\
\hline Fiore et $\mathrm{al}^{10}$ & 5 & Negative & Ocular (5) & $\begin{array}{l}\text { Topical glaucoma } \\
\text { medication (5) }\end{array}$ \\
\hline Thiel et al ${ }^{11}$ & 1 & Negative & Ocular** & Oral sulfadoxine \\
\hline
\end{tabular}

- Synonyms: BMM, ocular pemphigoid.

† $\mathbf{N}=$ number of patients classified as drug-induced cicatricial pemphigoid, as drug-induced mucous membrane pemphigoid, or as drug-induced ocular pemphigoid. In some of the cases a definite clinical cicatrization was observed.

$\ddagger$ IF $=$ immunofluorescence examination of the skin.

SIF not done or not available.

In Number of patients in parentheses.

- This patient also had erythema exudativum multiforme lesions of other mucous membranes and of the skin.

classification. A conspicuous linear deposition of IgG and complement, however, was observed along the basement membrane of the buccal mucous membrane. There were no clinical signs of $\mathrm{CP}$ at this site.

On IF examination, the serum samples did not contain basement membrane autoantibodies, but did contain an- tinuclear antibodies in the absence of anti-DNA antibodies. Intercellular pemphigoid-like antibodies (titer $1: 40$ ) were also detected using guinea pig lip as the substrate, but 2 months after stopping the practolol treatment, these autoantibodies had disappeared. ${ }^{3}$ Practolol was withdrawn from the market in 1975 because of a high inci-

Figure 1. Drug-induced cicatricial pemphigoid of the ocular mucous membrane caused by oral practolol (Eraldin).

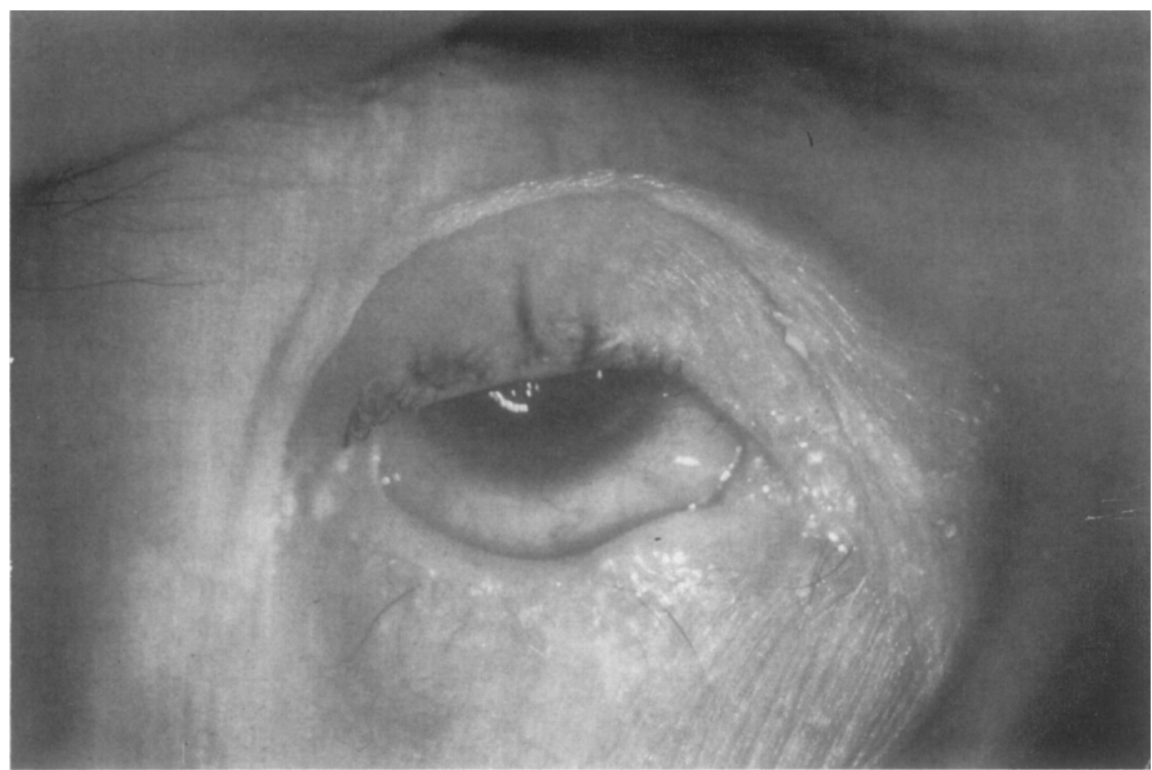




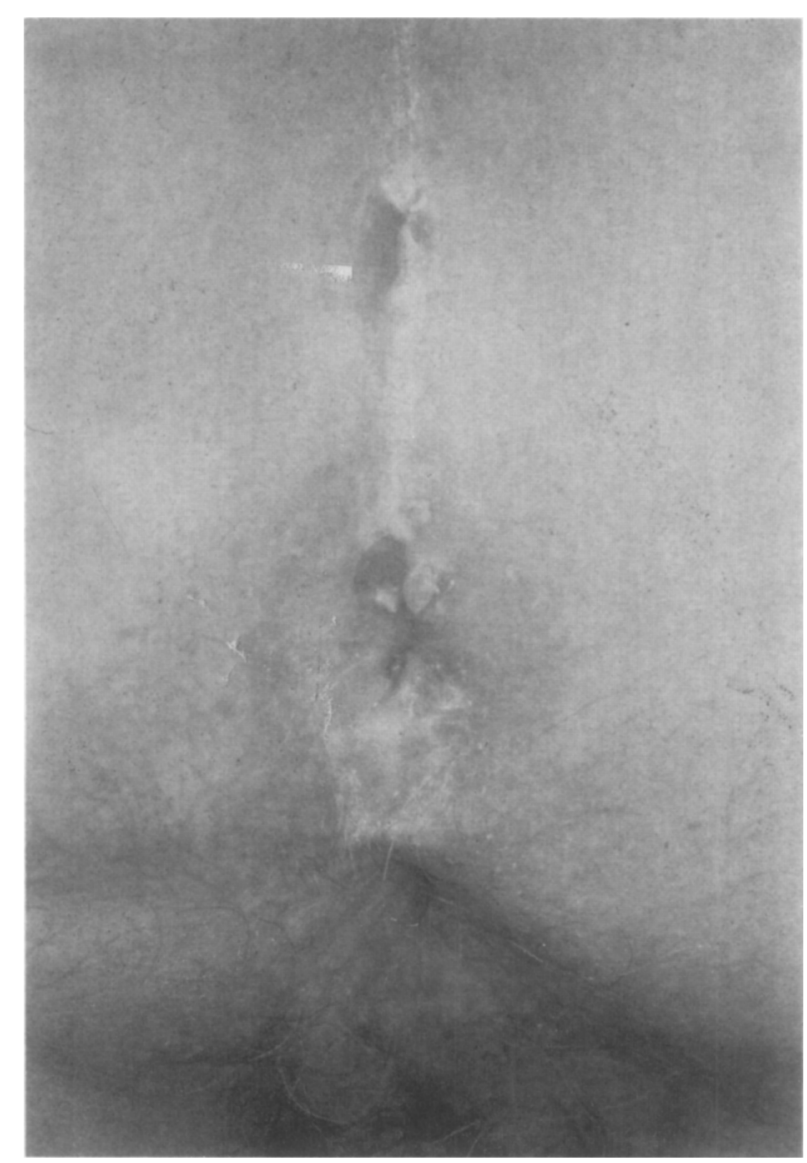

Figure 2. Drug-induced cicatricial pemphigoid of the anal and perianal regions caused by clonidine (Catapresan).

dence of serious side effects on the skin and several other organs, including sclerosing peritonitis.

\section{Case Report 2}

A woman, aged 59 years, treated for systemic hypertension with clonidine (Catapresan) (daily oral dose two or three 0.250 -mg capsules) for 2 years, developed a blistering cicatricial eruption with primary localization on the mucosal surfaces of the vulva and the anus with perianal extension (Figure 2).

Histopathologic examination of the perilesional skin adjacent to a blister on perianal skin showed subepidermal blister formation at the basement membrane (Figure 3 ). A cellular infiltrate consisting predominantly of lymphocytes and neutrophils and, to a lesser extent, eosinophils was seen diffusely in the upper dermis and around the blood vessels. No clear fibrosis of dermal tissue was observed in the biopsy that was examined.
Immunofluorescence studies on sections of perianal skin adjacent to the blister formation showed predominantly a linear deposition of $\mathrm{IgG}$ and complement along the basement membrane (Fig 4). Basement membrane autoantibodies were not detected in the serum.

Reappearance of skin lesions localized at the anal and perianal regions, this time accompanied by erythematous nonblistering eruptions on the breast, and abdomen, after reexposure to clonidine was highly suggestive of a relationship between the drug and the development of a syndrome that was classified as CP. ${ }^{6}$

In addition to the cardiovascular drugs implicated in these two cases of $\mathrm{CP}$, nonsteroidal anti-inflammatory drugs (NSAIDs) and D-penicillamine have also been implicated in the development of $\mathrm{CP}$.

Two cases classified as MMP were apparently induced by a NSAID. 9 Both patients had received indomethacin for rheumatoid arthritis. MMP developed in both patients 6 and 8 weeks respectively after treatment with this drug. In the same report, the authors stated that in a retrospective study it appeared that five other patients with MMP observed previously had all taken NSAIDs in the 6 months prior to the onset of the skin lesions.

Patients with rheumatoid arthritis who developed CP after the introduction of D-penicillamine (D- $\beta_{1}, \beta_{2}$-dimethyl cysteine) have been reported ${ }^{5,8}$ (see Table 1 ). Although a direct link between the two conditions ( $C P$ and rheumatoid arthritis) may exist independently of the use of drugs, the possibility that $\mathrm{CP}$ was a complication of D-penicillamine treatment was considered more likely. ${ }^{8}$

Furthermore, ocular mucosal alterations classified as "ocular pemphigoid" have been reported to result from various topical treatments (see Table 1). In none of five patients with ocular pemphigoid induced by topical glaucoma medications were linear immunoglobulin and/or complement deposition along the basement membrane of lesional skin observed using IF techniques. ${ }^{10}$ In four patients, the lesions were self-limiting and nonprogressive after stopping the topical treatment. One patient, however, developed progressive scarring even though the offending medication had been discontinued. Because the IF examination was negative it is uncertain whether these cases represent true $C P$. The term cicatricial pemphigoidlike or ocular pemphigoid-like drug reaction is probably more appropriate on clinical and histologic grounds.

Of interest is a detailed report on a patient who developed exudative erythema multiforme major with massive involvement of the skin, oral mucous membranes, and mucous membranes of both eyes as a result of sulfadoxine, present as one of the constituents in the antimalaria drug Fansidar (sulfadoxine and pyrimethamine). ${ }^{11}$ The chronic inflammation of the eyes led to proliferation in the conjunctivae. The final clinical picture was compara- 


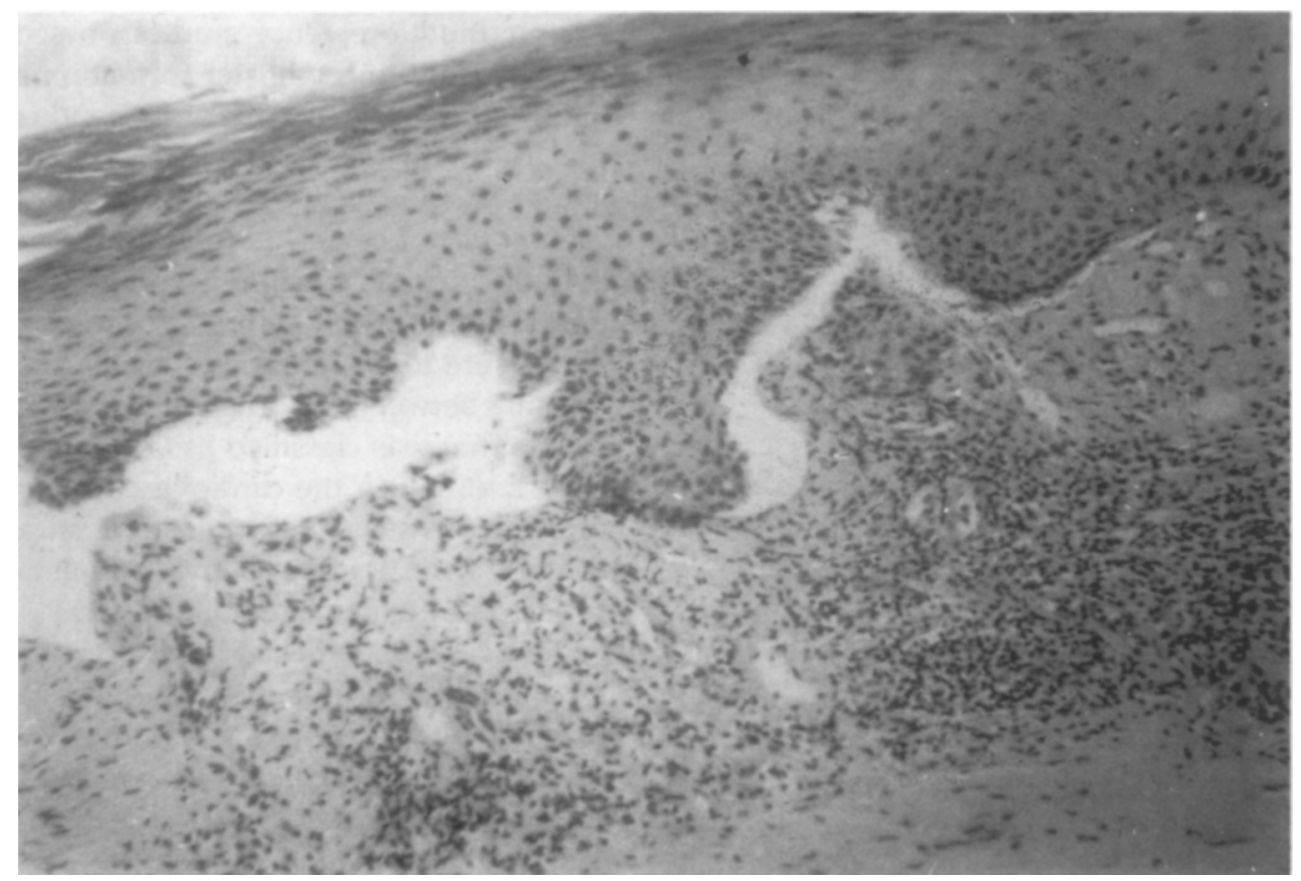

Figure 3. Subepidermal blister formation in drug-induced (clonidine) cicatricial pemphigoid (HE, $\times 250)$.

ble to that of severe (ocular) $\mathrm{CP}$, including the development of scarring and blindness in both eyes.

\section{Discussion}

Drug-induced MMP, particularly in the eyes, may be thought of as a spectrum of diseases. It may occur as a localized, nonprogressive, "toxic" reaction that remains self-limited once the offending topical medication is withdrawn; or it can progress relentlessly with scarring having the characteristic immunologic (IF) features of true $\mathrm{CP}$; or it can occur as a concomitant manifestation of other syndromes such as exudative erythema multiforme. ${ }^{10,11}$

In the two cases of drug-induced $\mathrm{CP}$ described here, the underlying pathomechanisms of the side effects remained unelucidated. A previous study indicated that during long-term topical ocular treatment with $\beta$-adrenergic receptor blocking agents, sensitization can occur as a result of delayed-type hypersensitivity. ${ }^{12}$ Interaction of $\beta$-adrenergic receptor blocking agents (practolol) or $\alpha$-adrenergic receptor stimulating agents (clonidine) with the cyclic AMP system in the epidermal (mucosal epithelial) cells may be operative. In view of the concept that at least a part of the basement membrane is of cpidermal origin, it is tempting to assume that the underlying factors involved in these cases of drug-induced $C P$ are related to local metabolic disturbances (cyclic AMP sys- tem?) in the germinal cells. This could lead to the deposition of immunogens in the basement membrane and may subsequently lead to the induction of cellular immunity and/or to the formation of autoantibodies and of immunecomplexes in situ. Other drugs might also play a role in such metabolic disturbances. In this respect, it is interesting that serum autoantibodies with affinity for the cytoplasm of epithelial basal cells have been observed in patients on different drugs and with different clinical adverse effects (eg, exudative erythema multiforme and vasculitis). ${ }^{13,14}$

Another possible explanation for the elicitation of autoantibodies comes from the experience that prostaglandins of the E series inhibit the expression of major histocompatibility class II antigens (Ia antigens) by murine macrophages and human Langerhans cells. ${ }^{15}$ Drugs like indomethacin (see Table 1), that inhibit prostaglandin synthesis have been shown to increase the expression of Ia antigens by these cells, mimicking the action of Ia-inducing lymphokines such as gamma interferon. It has been suggested that increased Ia expression enhances humoral immune responses. ${ }^{16}$ Thus, indomethacin and other cyclooxygenase inhibitors might exacerbate autoimmune disease through such mechanisms.

Drugs may have alternating effects on both the humoral and the cellular limbs of the autoimmune response. A mononuclear inflammatory infiltrate may be present in the skin lesions of (disseminated) bullous pemphigoid 


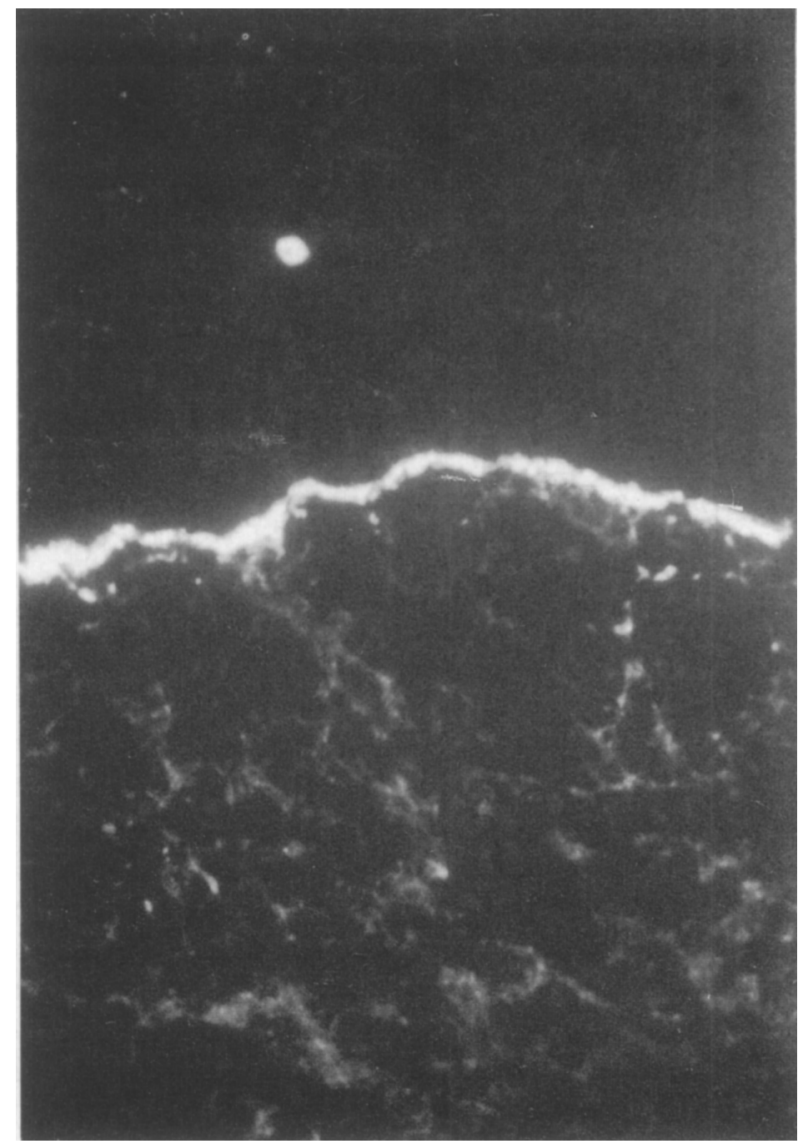

Figure 4. Immunofluorescence study. Border of a subepidermal blister. Predominantly linear fluorescence (IgG/ FITC staining) along the basement membrane in drug-induced (clonidine) cicatricial pemphigoid $\times 500)$.

(BP), but usually mononuclear infiltrates are predominant in the lesions of the chronic localized variants of the disease (CP and LBP). This observation may favor a possible role of $\mathrm{T}$ cell-mediated immunity in terms of antigen-processing (including immunogens precipitated by drugs) in the early events of this disease complex and probably also in the perpetuation of the disease. ${ }^{17,18}$

Important observations have been reported in active BP in favor of "in situ" presentation of antigens located in the basement membrane to $\mathrm{T}$ cells. ${ }^{17,19} \mathrm{~A}$ redistribution of Langerhans cells toward the basement membrane and an increase in the total number of Langerhans cells in the lesional skin have been observed. ${ }^{17}$ Furthermore, in $\mathrm{BP}$ significantly increased numbers of helper-T cells and of HLA-DR-positive T cells in the peripheral blood were observed. ${ }^{18}$ These data may suggest that helper-T cell activation may be involved in the acute phase of the disease. ${ }^{18}$ In addition, in BP, a decreased level of interleukin2 (IL-2), assumed to be caused by the consumption of IL-2, has been reported. ${ }^{19}$ Thus, T cell-mediated reactions may be an important link in the inductive phase of immunity leading finally to subepidermal bullous autoimmune disorders. Particularly in BP, the formation of "antigen (BM)-antibody-complement complexes" is thought to play a key role in the chemotaxis of eosinophilic granulocytes and in blister formation. ${ }^{20}$ Tissue injury based on circulating autoantibodies may be understood better in cases of BP than in the localized chronic variants of the disease (LBP and CP).

In LBP, the predominance of activated helper/inducer $T$ cells in the dermoepidermal regions as well as the expression of IL-2 receptor (IL-2R) on eosinophils in the dermal infiltrate have been observed. ${ }^{21} \mathrm{IL}-2 \mathrm{R}$ can be expressed not only by $\mathrm{T}$ cells, but apparently also by nonlymphoid cells. Subsets of activated $T$ cells may possibly produce precursors of eosinophils. This may favor antigen processing at the local level, leading to $\mathrm{T}$ cell-mediated recruitment of eosinophils. ${ }^{21}$ LBP resembling fixed drug eruption has been reported. ${ }^{22}$ Processes mediated by $T$ cells similar to those described earlier might also play a role in the different drug-induced variants of pemphigoid, particularly in drug-induced CP. Future studies are required to establish the exact role of $T$ cells in drug-induced pemphigoid variants. In the case reviewed earlier in this chapter in which drug-induced CP developed together with exudative erythema multiforme lesions, the lymphocyte transformation test with the drug considered as responsible (sulfadoxine) remained positive at least 18 months after the onset of the disease. ${ }^{11}$

\section{Drug-Induced Acquired Epidermolysis Bullosa}

Important clinical criteria for acquired epidermolysis bullosa (AEB) are trauma-induced blisters occurring over the joints of the hands, feet, and elbows; additional atrophic scars; milia; and nail dystrophy. There is no family history and there is postinfancy onset of the disease. On the ultrastructural level the blister formation occurs beneath the basal lamina, with a zone of amorphous material beneath the basal lamina remaining on the epidermal side of the blister. ${ }^{23}$

Apart from neutrophils, a mild chronic inflammatory (lymphohistiocytic) perivascular infiltrate may be present in the lesions. In the majority of cases, the immunoreactants in the basement membrane are of the IgG class, but $\operatorname{IgM}, \operatorname{IgA}$, and complement deposition at this region may also be present in some patients. ${ }^{24}$ Circulating IgG antibodies against the basement membrane are usually not detectable in the serum. There is some evidence that AEB is in linkage disequilibrium with the MHC class II allele HLA-DR ${ }_{2}{ }^{25}$ The immune cascade in AEB has yet to be elucidated, but in the inflammatory variant of the disease, 
neutrophils are suspected to play an important role in tissue injury. ${ }^{24}$

The results of previous studies at the ultrastructural level indicate that IgG depositions in both BP and CP are located in the lamina lucida or the lamina basale. ${ }^{24,26}$ In AEB, the ultrastructural location of immunoglobulins has been observed to occur just beneath the lamina densa, ${ }^{23,26}$ which does not support the hypothesis that AEB may be a variant of pemphigoid. ${ }^{27}$ Drug-induced skin eruptions classified as AEB-like disease have been described apparently as a result of sulfonamides, ${ }^{28}$ sulfamethoxypyridazine, $^{29}$ D-penicillamine, ${ }^{30-32}$ and furosemide ${ }^{33}$; however, in most of these reports the definite proof for this classification was lacking.

Furosemide, in high doses, is used extensively to treat edematous patients with chronic renal failure. Seven patients developed a skin syndrome classified as AEB while on high-dose furosemide treatment. ${ }^{33}$ These cases are described here in more detail. Of the seven patients (five men and two women, aged 17 to 57 years), three had glomerulonephritis; the other diagnoses were pyelonephritis, polycystic disease, secondary amyloidosis, and polyarthritis nodosa. Renal function was seriously impaired in six patients (creatinine clearance 4$10 \mathrm{~mL} / \mathrm{min}$ ) and the remaining patient had refractory edema associated with the nephrotic syndrome. The dose of furosemide ranged from 0.5 to $2.0 \mathrm{~g} /$ day and most patients had received a high dose of this drug for several months before the skin lesions appeared. The shortest duration of treatment was 2 months and the longest, 3 years. Superficial bullae, up to $3 \mathrm{~cm}$ in diameter, were situated on the dorsum of the fingers or hands and, in two patients, also on the dorsum of the feet. The lesions were itchy, but without systemic manifestations. The bullae were superficial, leaving a raw surface, and filled with clear fluid. Minor trauma had predisposed to the development of the bullae. Porphyrin studies on urine, feces, and blood were carried out in three patients. The results were negative in all three cases. Skin biopsy showed a subepidermal blister with very few inflammatory cells in the blister fluid and minimal inflammatory infiltrate in the dermis. The condition appeared clinically and histologically to be AEB. The lesions persisted for 3 to 9 weeks and then healed, whether or not furosemide was continued. ${ }^{33}$

\section{Discussion}

Dermatologic complications attributed to the use of furosemide are rare. Furosemide as the cause of drug-induced bullous pemphigoid (BP) has also been reported. ${ }^{34,35}$ The mechanism of blistering in drug-induced AEB-like skin eruptions is obscure. Although its onset in relation to high-dose furosemide is extremely suggestive, the blistering tendency subsides in weeks or months, whether or not large doses of furosemide are continued. An important primer role for immunologic mechanisms seems to be unlikely in the cases described. It is tempting to speculate that the drug, particularly at high doses, interferes with tissue metabolism in the dermoepidermal region in a manner that depends on light exposure, inducing what is clinically an acquired form of epidermolysis bullosa.

\section{Conclusions}

It can be concluded that both cicatricial pemphigoid and acquired epidermolysis bullosa, or patterns closely mimicking these syndromes, may be triggered by the use of certain drugs. Ocular treatment with topical drugs can lead to a syndrome that clinically resembles ocular pemphigoid; however, the results of immunofluorescence studies on the tissue in a number of cases reported in the literature and reviewed in this article were either negative or not available (see Table 1). Therefore, a definite classification cannot be established. Moreover, we think that in the majority of cases with lesions induced by topical drugs, the term ocular pemphigoid cannot be considered an appropriate synonym for cicatricial pemphigoid because fibrosis and cicatricial lesions are absent.

Systemic treatment with certain drugs more evidently may trigger a syndrome compatible with true cicatricial pemphigoid in which, besides the mucosal membranes, the skin may also be involved (see Table 1).

Further studies on the interference of drugs with tissue metabolism in the skin and on the aberrant immune responses in cicatricial pemphigoid and acquired epidermolysis bullosa will cast more light on the role of drugs in the pathomechanisms of these blistering disorders.

\section{References}

1. Hardy KM, Perry HO, Pingree GC, et al. Benign mucous membrane pemphigoid. Arch Dermatol 1971;104:467-75.

2. Bean SF. Cicatricial pemphigoid. Immunofluorescent studies. Arch Dermatol 1974;110:552-5.

3. Van Joost Th, Crone RA, Overdijk AD. Ocular cicatricial pemphigoid associated with practolol therapy. Br J Dermatol 1976;94:447-50.

4. Patten JT, Cavanagh HD, Allansmith MR. Induced ocular pseudopemphigoid. Am J Ophthalmol 1976;82:272-6.

5. Pegum JS, Pembroke AC. Benign mucous membrane pemphigoid associated with penicillamine treatment. Br Med J 1977;1:1473. 
6. Van Joost Th, Faber WR, Manuel HR. Drug-induced anogenital cicatricial pemphigoid. Br J Dermatol 1980; 102:715-8.

7. Hirst LW, Werblin T, Novak M, et al. Drug-induced cicatrizing conjunctivitis simulating ocular pemphigoid. Cornea $1982 ; 1: 121-8$.

8. Shuttleworth D, Graham-Brown RAC. Cicatricial pemphigoid in a D-penicillamine treated patient with rheumatoid arthritis. Br J Dermatol 1985;113 (suppl 29):89-90.

9. Harrington $\mathrm{CI}$, Messenger AG. Dermatitis herpetiformis [correspondence]. Br J Dermatol 1986;114:265-7.

10. Fiore PM, Jacobs IH, Goldberg DB. Drug-induced pemphigoid. A spectrum of diseases. Arch Ophthalmol 1987; 105:1660-3.

11. Thiel HJ, Richter U, Pleyer U, et al. Drug-induced exudative erythema multiforme major with chronic proliferation of the conjunctiva and bilateral blindness. Clinical course and immunohistological study. Klin Monatsbl Augenheilkd 1990;197:142-9.

12. Van Joost Th, Middelkamp Hup J, Ros FE. Dermatitis as a side-effect of long-term topical treatment with certain betablocking agents. Br J Dermatol 1979;101:171-6.

13. Van Joost Th. Serum antibodies with affinity to the cytoplasm of epidermal basal cells. In Beutner $\mathrm{EH}$, Chozelski TP, Bean SF, et al, editors. Immunopathology of the skin. 2nd ed. New York: Wiley, 1979:473-87.

14. McQueen A, Behan WMH. Immunofluorescence microscopy. The "string of pearls" phenomenon: An immunofluorescent serological finding in patients screened for adverse drug reactions. Am J Dermatopathol 1982;4:155-9.

15. Snyder DS, Beller DI, Unanue ER. Prostaglandins modulate macrophage Ia expression. Nature 1982;299:163-5.

16. Janeway CA Jr, Bottomly K, Babich J, et al. Quantitative variation in la antigen expression plays a central role in immune regulation. Immunol Today 1984;5:99-105.

17. Emtestam L, Hovmark A, Lindberg M, et al. Human epidermal Langerhans cells in bullous pemphigoid. Acta Derm Venereol (Stockh) 1987;67:529-32.

18. Schaller J, Haustein UF, Fiebig G. T-helper cell activation in bullous pemphigoid. Acta Derm Venereol (Stockh) $1987 ; 67: 520-3$.

19. Ahmed AR, Hijri K, Arab-Kermani V. Interleukin-2 production in bullous pemphigoid. Arch Dermatol Res 1984;276:330-2.
20. Jordon RE. Complement activation in bullous skin diseases. J Invest Dermatol 1975;65:162-9.

21. Van Joost Th, Vuzevski VD, Ten Kate F, et al. Localized bullous pemphigoid: A T cell-mediated disease? Electron microscopic and immunologic studies. Acta Derm Venereol (Stockh) 1989;69:341-4.

22. Fellner MJ, Engber P. Localized bullous pemphigoid resembling fixed-drug eruption. NY State J Med 1979;79:1085-7.

23. Roenigk HH Jr, Pearson RW. Epidermolysis bullosa acquisita [editorial]. Arch Dermatol 1981;117:383.

24. Nieboer C, Boorsma DM, Woerdeman MJ, et al. Epidermolysis bullosa acquisita. Immunofluorescence, electron microscopic and immunoelectron microscopic studies in four patients. Br J Dermatol 1980;102:383-92.

25. Gammon WR, Heise ER, Burke WA, et al. Increased frequency of HLA-DR $\mathrm{D}_{2}$ in patients with autoantibodies to epidermolysis bullosa acquisita antigen: Evidence that the expression of autoimmunity to type VI collagen is HLA class allele associated. J Invest Dermatol 1988;91:228-32.

26. Niebuer C, Boursma DM, Woerdeman MJ. Immunoelectron microscopic findings in cicatricial pemphigoid: Their significance in relation to epidermolysis bullosa acquisita. $\mathrm{Br} \mathrm{J}$ Dermatol 1982;106:419-22.

27. Dahl MGC. Epidermolysis bullosa acquisia - A sign of cicatricial pemphigoid? Br J Dermatol 1979;101:475-84.

28. Burckhardt W. Arzneiexantheme. In: Jadassohn, editor. Handbuch der Haut- und Geslachtskrankheiten, Ergänzungswerk. Berlin: Springer, 1962;II/1:545-96.

29. Von Gossrau G, Haas R, Rössler W. Zur epidermolysis bullosa toxica. Dermatol Wochenschr 1967;153:394-402.

30. Beer WE, Cooke KB. Epidermolysis bullosa induced by penicillamine. Br J Dermatol 1967;79:123-5.

31. Rimbaud P, Mirouze J, Mary P, et al. Complications dermatologiques au cours du traitement de la maladie de Wilson par la D-pénicillamine. Med Chir Dig 1973;2:3-8.

32. Brown MD, Dubin HV. Penicillamine-induced bullous pemphigoid-like eruption. Arch Dermatol 1987;1 23:1119 20.

33. Kennedy AC, Lyell A. Acquired epidermolysis bullosa due to high-dose frusemide [short report]. $\mathrm{Br}$ Med J 1976;1:1509-10.

34. Ruocco V, Sacerdoti G. Pemphigus and bullous pemphigoid due to drugs. Int J Dermatol 1991;30:307-12.

35. Van Joost Th, Tank B, Stolz E, et al. Causative agents and pathogenicity in iatrogenic cutaneous autoimmunity. Int $\mathrm{J}$ Dermatol 1987;26:75-9. 